\title{
Growth Strategy of PASECO as a Global Electronic Company: Focusing on the Middle East Market
}

\author{
Byoung-Goo KIM' ${ }^{1}$, Chun-Su LEE ${ }^{2}$ \\ ${ }^{1}$ First Author Associate Professor, Division of Global Business, Hanshin University, Osan, Korea \\ E-mail: bgkim@hs.ac.kr \\ 2 Corresponding Author Professor, Department of International Commerce, Pukyong National University, Busan, Korea. \\ E-mail: leecs@pknu.ac.kr
}

Received: November 12, 2019. Revised: December 11, 2019. Accepted: December 24, 2019.

\begin{abstract}
Purpose - This study aims to analyze PASECO's environment and strategies during its advance into the Middle East to find out the success factors of the kerosene heater market and provide strategic implications for small and medium enterprises' growth based on these factors.

Research design and methodology - This study analyzes the success factors of companies operating in the Middle East. As a case analysis study, the method of research analyzes case enterprises through existing literature, newspaper articles, and corporate interview materials.

Results - PASECO's success was shown by its high technological power in kerosene heater products, understanding customers' needs, understanding the Middle East market and localization strategy.

Conclusions - PASECO has been constantly developing R\&D capability to secure competitive products and has released localized products to enhance the satisfaction of its customers in the Middle East and has also been successful by constantly creating new opportunities. The firm's success strategies provide implications for small and medium-sized businesses for greater growth.
\end{abstract}

Keywords: Core competence, Middle East market, Kerosene heater, Localization

JEL Classification Code: F23, L21. 


\section{Introduction}

In general, firms are trying to use their own management resources to establish competitive advantages within their own industries, which will play an important role as a sustained growth engine for the enterprise. The reality, however, is that SMEs are having difficulty securing management resources to gain a competitive advantage because the size of their own resources is limited compared to large companies. The crucial question of how large resource-constrained SMEs will acquire and survive management resources in order to build a competitive advantage needed for sustained growth can draw implications from companies such as the "Hidden Champion".

The Hidden Champion is a hidden small business (small but strong company). It refers to a company with global competitiveness that ranks first to third in global market share and is not well known to the public. In Korea's economy, The Hidden Champions currently has a small influence at home, but has enormous competitiveness and a high market share abroad. However, the importance of Hidden Champion taking up enormous competitiveness and high market share overseas, and supporting the nation's economy is emerging.

In this regard, this study has significant implications for a company called PASECO, which has entered overseas markets as an industry that has been declining in Korea and is the world's No. 1 player in related industries. The brand that PASECO used to enter the Middle East is 'KERONA'. This is a luxury heater that people in Iraq, Jordan, and the Middle East really want. The name 'KERONA' is so unique that it is called the epitome of a kerosene heater in the Middle East. Previous research is lacking on how PASECO, a former heater wick producer, sold heaters in the Middle East, a hot country, and topped the world with a 50 percent global share.

In the mid-' $80 \mathrm{~s}$, not long after PASECO entered the kerosene heater business, residential culture of apartments rapidly spread, consumers were enthusiastic about the apartment central heating system and the domestic kerosene heater market began to shrink sharply. At a time when more than 120 heater companies were closing down one after another, PASECO rather concentrated more on developing technologies to differentiate its oil-fired products. As a result, it acquires a tricky UL certification for fire-resistant and shock-resistant in America and pioneered a new market called the United States in 1994(Cho et al. 2016). Since then, the company has emerged as the No. 1 kerosene heater in the US after five years of incredible growth. The company has advanced into the Middle East with its strong momentum, and has occupied $60-70 \%$ of the Middle East kerosene heater market with its brand, KERONA, in just over 10 years. At the time when everyone turned away from kerosene heaters, PASECO products, which had followed the opposite path, are exported to about 23 countries including Europe, Australia, Russia, and Japan and informed the world that it was the top company in terms of market share with 60 percent of the global kerosene heater market in 2014.

PASECO has been selected by the Korean government several times as an excellent company with high quality competitiveness in recognition of its national prestige and outstanding technological power, and received INNOBIZ certification for technological innovation in 2007, and was selected as one of the world's leading product producers in 2006 and 2011. The purpose of this study is to analyze the process and success of PASECO, a Korean kerosene heater company, overcomes the crisis in the domestic kerosene heater market, which was on the decline. In particular, this study aims to analyze PASECO's environment and strategies during its advance into the Middle East and to identify the success factors and drivers of the kerosene heater market, and to provide strategic implications for the growth of small businesses based on these factors.

\section{Brief History of PASECO}

PASECO started with Shinwoo Textile Industrial Company, which was founded in August 1974 by Chairman Yoo Byoung-jin with the aim of producing wick for Kerosene Heater. It changed its name to Wooshin Electronics Co. in 1980 and changed its name to PASECO, which means Perfect product, Ace service, Smart Electronics, Company, and is currently the Yoo il-han CEO who is the eldest son of the company. The flagship products include kerosene heaters and hot air blowers, and over $90 \%$ of the total production of these heaters is exported overseas. The main domestic product is built-in kitchen appliances, and $95 \%$ of the total production is sold to the domestic market, $60 \%$ of which are supplied to OEMs such as Genesis BBQ, Samsung Electronics, and Hanssem, and $40 \%$ of them are sold in PASECO's direct sales stores. PASECO's overseas sales account for about 55 percent of its total sales, and products are exported to a total of 23 countries, including the United States, the Middle East, Europe, Asia and Africa (Lee, 2015). 
Table 1: Growth History of PASECO

\begin{tabular}{|c|c|l|}
\hline Growth Stage & Year & \multicolumn{1}{|c|}{ Content } \\
\hline \multirow{2}{*}{ Startup } & 1974.08 & $\begin{array}{l}\text { Establishment of Shinwoo Textile Industrial Company } \\
\text { - Production of Kerosene heater wick }\end{array}$ \\
\hline \multirow{4}{*}{ Growth } & 1980.06 & Manufacturing Kerosene Heater \\
\cline { 2 - 4 } & 1987.06 & Korea's First Butane Gas Burner Exports to U.S. \\
\cline { 2 - 4 } & 1993.07 & Export of Kerosene Heater with KERONA (PASECO's Brand) \\
\hline \multirow{2}{*}{ Leap } & 1994.04 & Kerosene Heater UL Mark Authentication \\
\hline \multirow{4}{*}{ Diversification } & 1999.10 & Rename company to PASECO \\
\cline { 2 - 4 } & 2000.05 & Obtain a French patent for an automatic fire extinguisher device \\
\cline { 2 - 4 } & 2003.04 & $\begin{array}{l}\text { Contract to supply finished products to GE for the first time in Korea's small and } \\
\text { medium-sized enterprises (Gas Cooktop) }\end{array}$ \\
\cline { 2 - 4 } & 2006.07 & $\begin{array}{l}\text { Selected as World's Top Commodities Award for Wick Kerosene Heater } \\
\text { (Ministry of Commerce, Industry and Energy) }\end{array}$ \\
\cline { 2 - 4 } & 2011.12 & $\begin{array}{l}\text { Selected as World's Top Commodities Award } \\
\text { (hot air fan) }\end{array}$ \\
\cline { 2 - 4 } & 2018.11 & $\begin{array}{l}\text { Selected as the best companies in quality competitiveness(17th, 11 consecutive } \\
\text { times) }\end{array}$ \\
\hline
\end{tabular}

PASECO's position in overseas markets has achieved $60 \%$ of the global kerosene heater market as of 2014, and has topped the global market share (Herald Economy, 2019). PASECO operates the institute's organization as three organizations: the Consumer Electronics Research Team, the Electronic Research Team and the Thermal Research Team, and is recognized for its independent technical skills by investing 1.5 percent to 2 percent of its sales every year. As of 2018, This Company gained overseas certifications from Germany, France, Canada, Japan, China and Russia, as well as UL certification UL (Underwriters Laboratories Inc.) Mark, the world's largest industrial standard in electrical and electronic fields governed by the American Insurance Manufacturers Association, is virtually impossible to advance into the U.S. market without this mark. by the U.S. and also has 41 patents, 26 practical new design rights, 61 design rights and 40 trademark rights (Lee, 2017).

Table 2: Current Status of PASECO R\&D Expenses and Patents

\begin{tabular}{|c|c|c|c|c|}
\hline Category & 2015 & 2016 & 2017 & 2018 \\
\hline R\&D Expenses & $1,919,303$ & $2,954,446$ & $2,055,532$ & 952,915 \\
\hline Percentage to Sales & $1.58 \%$ & $1.92 \%$ & $1.69 \%$ & $1.93 \%$ \\
\hline patent etc. & \multicolumn{4}{|c|}{$\begin{array}{c}\text { 41 patents, 26 practical new design rights, } \\
\text { 61 design rights and 40 trademark rights etc. }\end{array}$} \\
\hline
\end{tabular}

Source: Korea Investor Relations Service (2018)

More specifically, PASECO's business structure can be divided into seasonal appliances such as oil heaters and household appliances. Wick oil heaters and industrial heaters, the flagship products of PASECO's seasonal appliances sector, are exported to more than 40 countries around the world. In particular, it is recognized as the best in the Middle East and was selected as the World's premier product under the auspices of the Ministry of Trade, Industry and Energy.

Oil-heater industry grew steadily until the early 1990s. However, with the emergence of alternative heating products or changes in heating patterns, export weight is expanding rather than domestic market. As a result, PASECO pioneered the oil heater market mainly in the desert region of the Middle East, where the temperature gap is large and heating is essential after evening. By spreading it to Russia or the Americas, it has a market share of $60 \%$ in the Middle East, $45 \%$ in the U.S., and 40\% in Russia, thus maintaining a $40 \%$ global market share. 


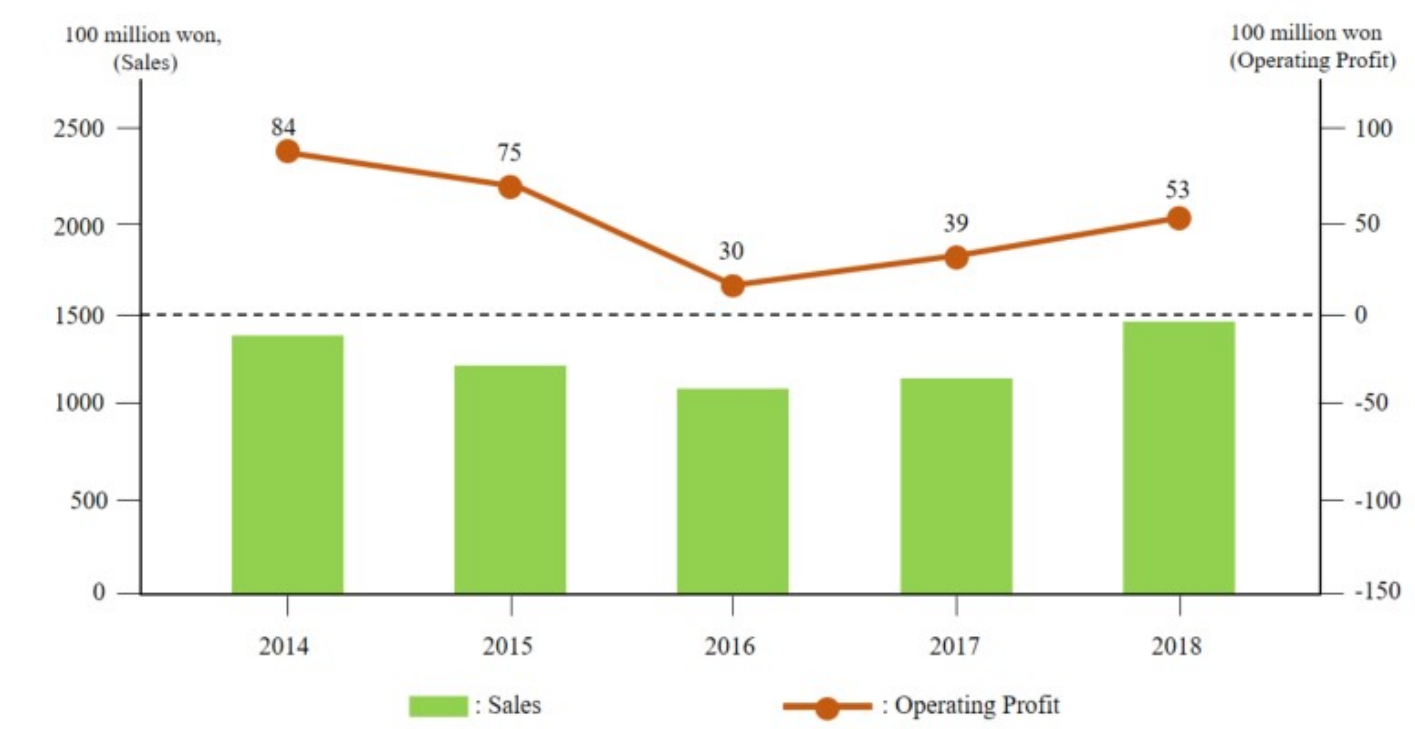

Source: Korea Investor Relations Service (2018).

Figure 1: Sales and Operating Profit of PASECO

PASECO has taken a leap forward recently because he started the built-in home appliance business. The oil heater business was plagued by poor off-season performance due to seasonal factors. As a result, the company began to produce products such as electric fans and gas heater, and entered the built-in appliance market in the 1990s as it signed a contract with Hanssem to supply dryware. PASECO has increased its size by supplying kitchen appliances such as dishwashers, gas cooktops, and hoods to domestic companies such as Samsung Electronics and Hanssem through OEM \& ODM method (Seo, 2018).

PASECO has seen its sales drop in recent years as its overseas export business has been on a gradual decline. PASECO recorded 138.1 billion won (operating profit 8.4 billion won), 121.4 billion won (operating profit 7.5 billion won), 121.3 billion won (operating profit 3.9 billion won) in 2017 and 149.4 billion won (operating profit 5.3 billion won) in 2018 (Korea Investor Relations Service, 2018).

Seasonal home appliances in PASECO inevitably experience volatility in demand depending on international situations and climate conditions, and the Islamic State terrorist attacks have led to a drop in exports to Iraq. However, due to the increased number of refugee camps in neighboring countries, shipments to the United Nations increased. In the first half of 2015, the export of oil was sluggish due to high temperatures in the southern hemisphere, the cold spell in the U.S. helped offset the growing market share. In addition, PASECO is breaking through the oil heater market, which is limited to market growth, by diversifying its products with electric heaters and fan heaters, and also steadily releasing products targeting the growing demand for camping (Cho, 2015).

As such, PASECO's biggest opportunity to grow will be to make inroads into overseas markets. In particular, entering the Middle East market and success played a very important role. The following will analyze how PASECO entered the Middle East market and what strategies the firm used to manage in the Middle East countries.

\section{Analysis of PASECO's entry into Middle Eastern countries}

\subsection{Current Status of PASECO in Middle East Markets}

The desert region of the Middle East is a hot place with temperatures ranging from 30 to 40 degrees Celsius during the day, but the temperature at night is below zero, making heating essential. PASECO's first export destination was Jordan, where 70 percent of the country's population is desert, with nomadic people accounting for a large portion. These nomads had tents and nomadic life, so mobile heating devices were essential (Seo, 2018). Before PASECO entered the market, rich nomads used expensive oil heaters, but poor nomads had to collect firewood and set bonfires. PASECO took note of this point and introduced a portable heater that can cook as well as 
heat. At that time, the Jordan market was dominated by high-priced Japanese oil heaters and low-quality, lowquality Chinese oil heaters, and PASECO launched high-quality but low-cost oil heaters, which are 65 percent of Japanese, targeting the very niche. This soon received much favorable response from nomads, and PASECO signed a deal with a local company supplying heaters across the Middle East in 1994.

PASECO's next Middle Eastern market was Iraq. The war between the United States and Iraq, which began in 2003, destroyed local power plants and oil fields in Iraq, and became a necessity for oil heater for homeless refugees. PASECO has succeeded in winning the rights of retailers with a network of Iraqi sales and has begun exporting between 500,000 and 800,000 units of the oil heater "KERONA" (brand of PASECO's oil heater) to Iraq. But suddenly, when KERONA's popularity soared, problems began to arise as many local retailers sold PASECO products. As the PASECO brand became saturated in the market, retailers began selling products at a flat price due to saturated supplies. As a result, PASECO faced a challenge of rapidly decreasing orders. Since then, the company has changed its policy to an exclusive agent system in distribution, supplying products to only one company and managing brand value. With this changed system, the company was able to gain an upper hand in its relationship with Middle Eastern retailers, which allowed it to choose favorable contract terms, such as setting a limit on orders and jointly paying for brand marketing costs with retailers (Jin et al., 2015).

To check PASECO's growing brand power, retailers suddenly demanded ODM, which produces products with their distribution brands. PASECO accepted the local companies' offer only on the condition that its brand orders should be triple the ODM (Kang, 2014). In addition, PASECO created a second brand called "Turbo" to solve the problem of distribution through exclusive contracts, and sold through other distributors, consistently keeping local retailers on edge.

PASECO is actively engaged in marketing activities such as TV, radio and newspaper advertisements in major Middle East markets. For example, a KERONA advertisement in a local Iraqi newspaper is actively promoting "Made in Korea." This is a reflection of the fact that the image of the Iraqi consumers is perceived as a premium, and PASECO is currently exporting the products to more than 10 Middle Eastern countries, including Iraq, Saudi Arabia, Jordan and Iran, through such active marketing activities.

\subsection{External Environmental Analysis: PEST Analysis}

This part will analyze the external environment of KERONA when entering the Middle East market. After analyzing the local PEST (Political, Economic, Social and Technological) environment, this study look at how this environment affected PASECO or brought about opportunities at the time of its entry into the market.

\subsubsection{Political Environment}

The Middle East was a time of relative stagnation in the 1990s due to moderate Arab policies and Korea has established diplomatic ties with some countries. But it was a time when diplomatic attention temporarily retreated as overall economic cooperation with the Middle East shrank following environmental changes such as the withdrawal of our builders following the outbreak of the 1990 Gulf War and the 1997 financial crisis. In the late 1990s, relations between South Korea and the Middle East began to pick up steam again in political and economic the brisk exchange of high-level officials has boosted cooperation between South Korea and the Middle East, and pushed to attract investment from South Korean companies in the Middle East.

In addition, as the era of high oil prices gradually re-emerged after 2000, Middle Eastern countries resumed construction of energy-related plants and social infrastructure, and in response, the Korean government actively engaged in sales diplomacy to promote bilateral cooperation channels, including joint committees and policy consultation with oil-producing countries in the Middle East, and to expand Korean companies' advance into the Middle East construction and plant markets. South Korea has also expanded its support for peace and economic development in the Middle East, which began in the early 1990s by expanding free aid to Palestine. As a result, the situation was favorable for PASECO to enter the Middle East market.

\subsubsection{Economic Environment}

In the 1990s, the Asian region experienced a general economic recession and the value of the won continued to fall. Japan, on the other hand, has been hit economically by the collapse of the bubble economy, lowering nominal interest rates. However, the yen continued to strengthen without directly being hurt by the yen's rise in real interest rates. In addition, Middle Eastern countries opened their markets in the 1990s under the neo-liberalistic policy and 
began to attract investment from foreign companies to revitalize the domestic economy. With the economy gradually developing, the timing of PASECO's entry could be considered appropriate.

\subsubsection{Social and cultural environment}

As a component of primary culture, in the case of climate, people in the Middle East need electric fans during the day and need heaters in the evening to live. Winter temperatures in northern Middle East countries such as Iran, Iraq and Jordan, which last for four months from November to February, are not as low as Korea's, but since the summer is so hot, the temperature in winter feels very low even if it's above zero. The temperature gap between day and night is also extreme, so there is a high demand for winter heating products, but the oil heater has seasonal limitations.

In the case of religion, Islam is overwhelmingly dominant. During Ramadan, sales of consumer goods such as food, clothing, home appliances and cars will increase by about 30 percent. To find out why, despite the solemn nature of Ramadan, consumption actually increases during this period, and there is a festive mood. This will lead to active marketing during this period to carry out intensive promotions.

The Amman region of Jordan in the Middle East is 70 percent desert, and there are many nomadic people (Jung, 2010). Also, Iraqis prefer oil heaters because the government provides a certain amount of oil for free (50 liters per month) (Kim, 2010). Therefore, Jordan and Iraq in the Middle East had strong needs for oil heaters.

\subsubsection{Technical environment}

In the worst business environment due to changes in the housing culture in Korea, PASECO rather sets up a R\&D team and engages in new technology development. The priority was to drastically improve wick as a core part of the oil-heater. The existing wick made of cotton had the disadvantage of having a lot of smoke and smell. To make inroads into overseas markets, overcoming the shortcomings of cotton wick was paramount. With the development of glass fiber called "Eglass" in Korea, PASECO was the first to develop a wick using glass fiber in 1988. The glass fiber wick has a long life and low fuel consumption, while the flame burns well (Oh, 1999).

\subsection{External Environmental Analysis: Porter's 5 Forces Analysis}

Porter's analysis of the industrial structure can understand the nature of competition as defined by the industry's structure, evaluate the attractiveness of the industry, and forecast changes in the industrial structure to be seen in the future, thus giving a prospect of future earnings. It is also a good analytical tool that can suggest ways of changing the industrial structure in a more proactive way (Porter, 2008).

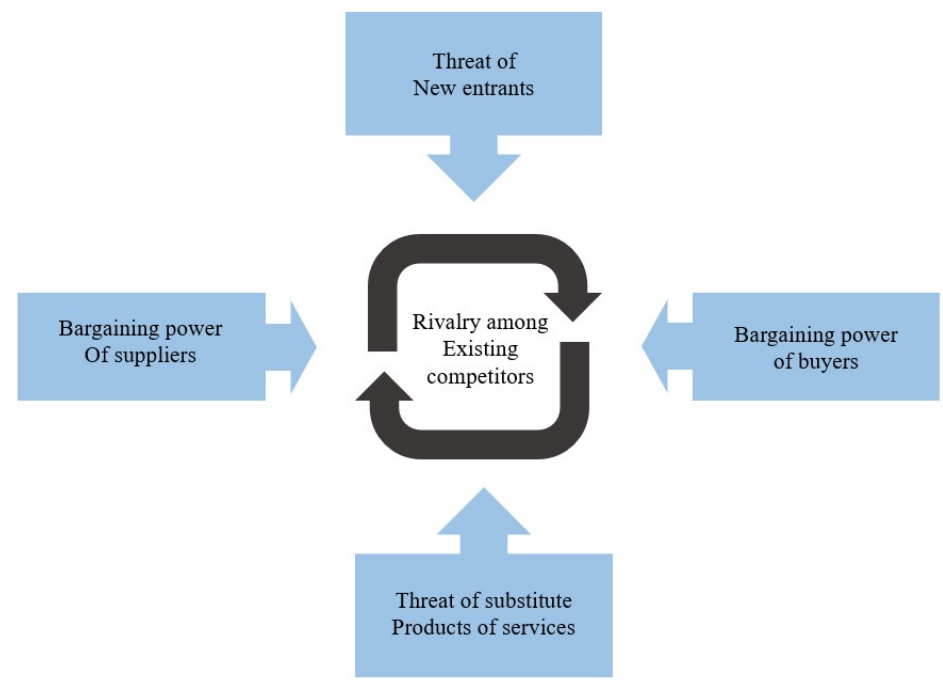

Figure 2: 5 Forces Model in oil heater industry 
In a brief look at the oil-heater industry, the biggest market for oil-heater is Japan. Except for Japan, there are not many areas where oil heaters are used as the main. Japan often uses oil heaters or electric heaters to heat indoors due to its traditional style of housing, the Tadami culture. Although the Japanese market is large as all other countries' demands combined, it is not easy for companies from other countries to enter the market due to the strict safety standards that require oil heaters and even earthquake-resistant designs. In the U.S., the oil heater is characterized by a reserve heating system in case electricity supply is cut off due to heavy snow and natural disasters. In the Middle East, oil heaters are used for the purpose of individual heating and cooking in areas where there is not enough social infrastructure.

\subsubsection{Rivalry among existing competitors}

First, it is industry concentration. At the time of entry into the market, one Japanese company including SENGOKU and TOYOTOMI had encroached on the market, and the concentration of the industry was high because a small number of companies were competing (KBS Special). Compared with the major competitors SENGOKU and TOYOTOMI in Japan, PASECO has less combustion products and better automatic fire extinguishing. SENGOKU, on the other hand, has the advantage of using a fuel tank with good corrosion resistance, but it has a weak point in automatic fire extinguishing and a lot of combustion products (Kang, 2014).

Second, homogeneity and heterogeneity of competitors. At the time, the Japanese companies that occupied the oil heater market in the Middle East were all targeting the middle class and the rich, but PASECO had a heterogeneity that targeted the common people differently.

Third, product differentiation. Although degree of differentiation of products between existing companies was low, PASECO entered the market early by differentiating products based on core technological power. And the oil heater industry has a high capital intensity, a huge production facility needs, and a high exit barrier.

Fourth, due to the nature of the oil heater industry, the initial fixed costs are higher than the additional variable costs. Whereas the cost of building production facilities is high, the long-term efficient productivity of existing workers can reduce variable costs if they acquire know-how while performing repetitive tasks.

\subsubsection{Bargaining power of suppliers}

Based on its higher technical skills than its competitors, PASECO is supplying products with higher reasonable price. PASECO developed its own glass fiber wick for the first time in Korea in 1988. Glass fiber wick is a fibershaped mineral fiber that has good thermal efficiency and enabled cost reduction as an inexpensive raw material. Based on such technology development, PASECO has dominated the Middle East market at low prices, not lagging behind in terms of quality, based on superior parts compared to Japanese products.

PASECO developed the world's first fire extinguishing equipment using a shape memory alloy in 1999. The device automatically turns off the oil heater when the temperature of the room reaches a certain level, keeps the levels of carbon monoxide and carbon dioxide nested in indoor air at harmless levels, and allows fuel to be refueled while burning without turning off the oil heater. With these innovative technologies, PASECO eliminated the need to use Belgium's existing patent technology, resulting in cost savings of about $\$ 10$ per unit (Oh, 1999).

PASECO had these technologies and quality when entering the market early on, but as a late-mover, the supplier's bargaining power was weak. However, it has become increasingly established in the market, and with continuous $\mathrm{R} \& \mathrm{D}$ and differentiated strategies and marketing, the supplier's bargaining power has also improved, taking the No. 1 position in the industry.

\subsubsection{Bargaining power of buyer}

Distribution companies, which are major buyers of PASECO products, are increasingly inclined to expand and strengthen their own brands, and this situation is likely to weaken their bargaining power in the future. As the exclusive agent in the Middle East market is seeking to brand itself, it is difficult to maintain the KERONA, PASECO's own brand. However, it is unlikely that KERONA will be easily swayed by retailers like the U.S. market, as it has long been a luxury brand with a solid reputation in the Middle East market.

Its bargaining power with distribution companies is likely to emerge as an important factor that will determine the profitability of the industry as a whole in the future. This is because the retail price of the product is low and there is not much demand, so there is very little profit in establishing its own distribution network (Myoung, 2010).

Given the characteristics of the oil-heater industry, PASECO, which has established a market-leading position, is expected to continue to reap stable returns in the future. However, future profitability will depend on whether the 
company can enter the Japanese market or improve its bargaining power by establishing its own brand in advanced countries, including the U.S. market.

As such, the buyer's bargaining power was low at the time of entry due to a small number of competitors in the Middle East's oil industry, while the buyer's bargaining power was relatively strong because it did not require switching costs for the buyer to switch suppliers.

\subsubsection{Threat of new entrants}

Chinese companies can be seen as major potential new entrants. The oil-heater industry, PASECO's main product, is protected by an unexpectedly high entry barrier due to its small market size. Although there are annual variations, the Middle East market, PASECO's main market, is estimated to be around $\$ 30$ to $\$ 50$ million. Such a small market size served as an opportunity for small and medium-sized companies like PASECO. Not only does the oil-heater industry require a certain amount of investment in the early stages of the business compared to the small market size, but it also has a long payback period and many years of manufacturing know-how is important. As a result, it is not easy for large companies or new companies to enter the market. With these entry barriers, companies that have already established a foothold in the market have the advantage of being able to keep their businesses (Kang, 2014).

PASECO can be seen as having an absolute cost advantage by having its own core component technology, and has achieved product differentiation through its long term trust relationship with customers and brand recognition. It has also maintained close ties with retailers through large discount stores and agents at its headquarters.

However, Chinese companies stole their designs and utility model rights and printed Made in Korea on PASECO's trademark and exported them throughout the Middle East, including Iraq (Won, 2010). In order to prevent such fake PASECO's products, PASECO has started to prevent counterfeit products by making special labels on tape for Taegeuk pattern, special waterway, and packaging boxes.

\subsubsection{Threat of substitute product}

Substitutes can be seen as electric and gas heaters. For electric heaters, accurate temperature control is possible and does not cause pollution. However, it has a cost disadvantage in terms of large electricity consumption, which costs a lot of maintenance and costs about 40 percent higher than the oil heater. It also has a disadvantage in terms of poor firepower and low heating effects for Middle Easterners, who prefer large residential areas. In the case of gas heaters, the product itself is relatively cheap, but it also has a weak firepower and a risk of explosion in the use of gas.

In addition, as the environmental pollution problem of fossil fuels such as coal and oil becomes more serious, alternative energy sources such as solar, bioenergy and wind energy are increasing, so it can be said to be a threatening substitute of PASECO when products based on them are released.

\subsection{Internal Environmental Analysis: Competitive Advantage and Core Competence}

PASECO's type of competitive advantage has the character of differentiation advantage. As a result of continuous investment in R\&D in the Middle East market, it was able to hold about 40 patents and 300 intellectual property rig hts at home and abroad until the early 2000s. This has become a barrier that no other competitor can follow in terms of component-based quality. PASECO had a differentiation advantage based on reasonable prices and high technical skills but was not satisfied with this alone. PASECO enhanced the value of customers in the market by making impr oved products through feedback with buyers and customers and actively managing customer relationships (CRM) th rough $\mathrm{A} / \mathrm{S}$ and quality improvement education (Kim, 2018).

PASECO's core competence includes differentiated core component technology, problem-solving skills and relati onships with customers. At the time of its foundation, it succeeded in domestically producing complete of "wick" th at are highly dependent on foreign countries through intensive R\&D investment for the first time in Korea, and 'glas $\mathrm{s}$ fiber wick' that was created as such is a core technology. Japanese companies, which were existing companies at $t$ he time, paid and used royalties on Belgium's patented technology, which produces less carbon monoxide and devic es that prevent the heater from overheating due to lack of oxygen in the air. However, PASECO has developed its o wn fire extinguishing device, using the shape memory alloy, and has the strength of development and suspension PA SECO's strength has driven existing companies to gain a relative cost advantage, even though oil heaters have alread y been differentiated (Oh, 1999).

In particular, the development of glass fiber wick is a driving force for PASECO to challenge the global market. Unlike in Korea, oil heaters were still used as useful heating and cooking tools in the Middle East and the United Sta 
tes. However, PASECO was not easy to enter as Japanese companies, which were technically superior, were already dominating the market. The development of glass fiber wick has become an important turning point in PASECO's a bility to enter these markets against the decline of the domestic market.

Through the development of glass fiber wick that is the most sensitive of the parts of the oil heater, PASECO cont ributed to the development of the oil heater industry by obtaining many industrial property rights and patents. PASE $\mathrm{CO}$ needed international certification to make inroads into overseas markets. Prior to entering the Middle East, PAS ECO succeeded in developing its own technology to minimize the smell and soot of oil heaters when it entered the U.S., allowing it to pass UL certification. In the process of acquiring the UL standard, problem solving knowledge w as acquired after many trials and errors. The phenomenon of separating the network surrounding the heater, which w as the biggest problem when entering the Middle East market, was solved by developing a groundbreaking structure through two months of collaboration with the institute. By making it possible for one person to do what was needed by four workers, it has resulted in significant labor cost savings.

The wick oil heater, which has become the foundation for PASECO's growth, is a product that has been judged to comply with Korean Agency for Technology and Standards for oil heater safety standards In order to pass the oil he ater safety standards, there shall be no conduction or fire concerns when the heater is tilted at 20 degrees after placin $\mathrm{g}$ about 50 percent of the oil in the oil canister of the heater horizontally on the tilting inversion test device. And has been turned off automatically when the heater falls or tilts due to sudden external shocks, thereby enhancing safety $i$ $\mathrm{n}$ particular. PASECO's products were applied with a one-touch device that ignites ignition by pressing the ignition 1 ever down, and a foot lever function to enhance ease of use and enhance the economy by using kerosene. The transp arent glass lights are more attractive at night, and the intensity of the lights is as bright as the eye can't blink, and it $\mathrm{h}$ as the characteristics of a lantern function (Korea Investor Relations Service, 2018). Based on this technology, the c ompany is recognized for its quality as it is exported to more than 40 countries including the Middle East and the Un ited States and Russia.

\section{Entry Strategy in the Middle East Market}

\subsection{Entry Strategy: STP Analysis}

When entering the Middle East market, PASECO's market segmentation was largely two methods. The first segmentation is a market where oil heaters are used as a necessity, where oil prices are cheap and gas or electricity is not supplied smoothly. The second is segmentation in terms of residential and cultural aspects. In the '80s, oil heaters were used as a necessity in Korea, but as the ' 90 s entered the '90s, the boom of apartment industries made the oil heater industry a decrying industrialization. Therefore, it was subdivided into the Middle East, where apartment culture has not been developed unlike Korea. The characteristics of this Middle East market include the use of essential materials for oil heaters, the lack of smooth supply of gas and electricity, and the development of apartment culture.

The Amman region in Jordan is characterized by most of the land being desert and populated mainly by nomadic tribes. Areas with a large distribution of nomadic tribes had to be moved once a month because they had to search for sheep's food, so the demand itself was high, but it was difficult to use gas or electric heaters. In addition, Iraq had a strong preference for oil heaters, with the state supplying 50 liters of oil per month free of charge per household. As results, oil heaters is used as a necessity in both areas where it is difficult to use electricity and gas despite the need for heating facilities. On the basis of these factors, PASECO targeted Iraq and Jordan.

PASECO has been positioned in South Korea as a differentiated product through its core technical skills. However, the Middle East market has already been eroded by more advanced products through the differentiation strategy of Japanese companies. However, the product was differentiated based on many patents and industrial property rights such as 'glass fiber wick' and 'automatic fire extinguishing device', which were core technologies obtained through continuous R\&D investment, and at the same time, it was able to gain an edge in price over Japanese companies' products due to its own technology development. This modified positioning resulted in the positioning of reasonable prices and good differentiated products that could be sold to all urban, rural or desert and nomadic customers.

\subsection{Entry Strategy: 4P Analysis}

\subsubsection{Product}


PASECO's main product in the Middle East is the oil heater. In the early days of the entry, PASECO found that Jordan's consumers, even in the Middle East, had to work hard because they were non-oil-producing countries with little oil, thereby finding that they were relatively efficient and price sensitive, and desert and nomadic. Based on this, the company released the product 'WKH-2310', which is reasonable price, using the latest technologies such as simple design and devices that automatically extinguish when a heater falls down. Also, to overcome the seasonal limitations of the heater, the product was launched with PET, a portable cooking heater that can be used as a heater at night with cooking functions during the daytime. In Iraq since 2003, the power of suppliers has been very high due to increased demand for oil fires. And local retailers have begun keeping PASECO in check. Distributors offered to supply existing PASECO's products through ODM method, while PASECO placed the condition that orders for its products should always be three times higher than those for ODM (Lee, 2016). It also created a second brand called 'Turbo' to solve the problem of distribution through exclusive contracts. It has consistently kept local retailers in check while selling the product through other retailers.

Oil heaters could only be exported to Europe by using devices to prevent a shortage of oxygen and prevent overheating and burners that emit less carbon monoxide (Jung, 2010). Because Belgium holds patents, most of the world's largest oil heater companies, including those in Japan, paid royalties to Belgian companies and applied the technology to their oil heater products. PASECO, however, has developed a technology that further upgrades this technology. Using the shape memory alloy, the oil heater automatically switches off when the temperature of the room reaches a certain level, keeps the levels of carbon monoxide and carbon dioxide contained in indoor air at harmless levels, and allows fuel to be refueled while the oil heater is burned without turning off.

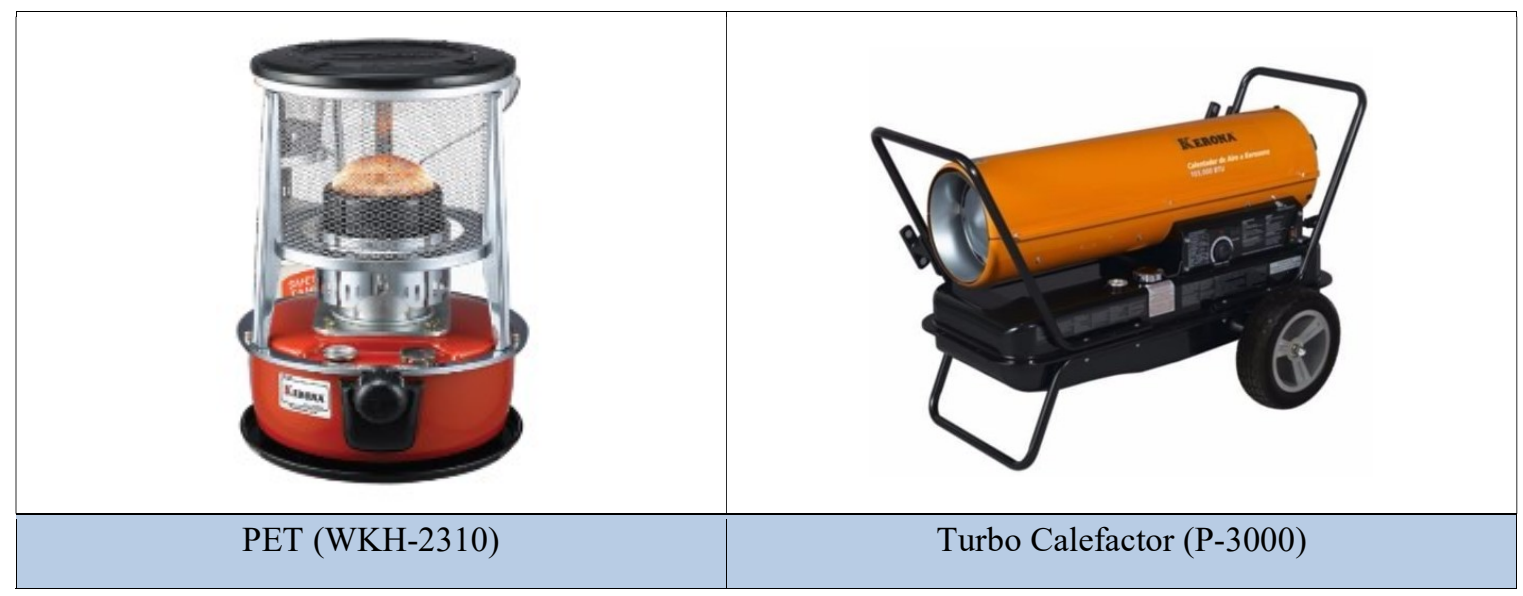

Source: PASECO

Figure 3: WKH-2310 and P-3000 Products

\subsubsection{Price}

The price of PASECO's oil heater in the Middle East was cheaper than that of Japanese companies and sold at a higher price than that of Chinese companies (KBS, 2005). When entering the Middle East market in the early stages, the company provided products that did not deteriorate in order to break the entry barrier due to the high quality of Japan. The company was able to internally produce 'glass fiber core' and 'automation device', which are key materials that helped produce high quality products, through its own technology. Therefore, despite product differentiation, WKH-2310 has a cost advantage over existing Japanese companies, with a price of \$11.95 USD PET.

\subsubsection{Place}

PASECO, like other heater companies, sold through a fireplace dealership in Jordan in the early days of its entry. But instead of relying solely on these dealership operations, they were able to distribute their products to large retailers, appealing to customers in need of heat, and potential consumers who did not know PASECO. PASECO's popularity has increased, allowing only a small number of retailers to supply products that were sold by all distributors (Jin et al., 2015). 


\subsubsection{Promotion}

PASECO, which has low awareness in the early days of its entry, has built up its awareness by conducting $1: 1$ door-to-door marketing campaigns to explain to customers the quality of its products by visiting houses in areas less affected by Japanese companies than in other Middle East countries. It also visited large buyers and conducted direct marketing that appealed to safety devices and core technologies (KBS, 2005). Although PASECO is an exportoriented company, it deployed its headquarters staff in various areas for the convenience of local customers as its products gained recognition in the Middle East market and its share increased. PASECO has taught customers free of charge how to replace their limbs for a certain period of time and eliminate deficiencies, and has been able to greatly enhance the company's image with its own visiting customer service. After entering Iraq, PASECO has actively engaged in marketing activities such as TV, radio and newspaper advertising. Also, PASECO continuously improve quality and build trust with customers based on the list of suggestions it received from customers and the product problems it experienced over the years (Jin et al., 2015).

\subsection{Entry Strategy: 4P Analysis}

The localization strategy was one of the biggest factors in PASECO's success in the Middle East market (Ahn, 2013). Since major Middle Eastern customers are nomadic people, the firm developed a heater "PET" that allows not only heating but also cooking, making products suitable for the local environment and culture. In addition, customer service has been strengthened to respond quickly to problems arising from the special nature of the Middle East. The company focused on customer service by establishing customer service center in various locations in the sales area and maintaining headquarter's staff.

This strategy not only improved the satisfaction of Middle Eastern consumers but also played an important role in developing products suitable for the characteristics of the Middle East as it could identify the frequent causes of failure around the customer service center (Kim, 2018). For example, oil heaters used in the Middle East have often broken down, as consumers have used low-quality oil. To solve these problems, PASECO frequently replaced the wick and tried to improve consumers' habits by educating them on ways to reduce the scope of repair compensation if they use bad oil. In addition, market information received from retailers was important to produce a customized heater in the Middle East, in which PASECO made efforts to select competent distributors in the Middle East. Through this effort, PASECO was able to successfully establish its brand KERONA as the preferred oil heater brand for Middle Eastern consumers (Jin et al., 2015).

\subsection{Comparative Analysis between PASECO and Major Competitors}

It can be seen as TOYOTOMI as PASECO's main competitor in the Middle East market. First, when comparing and analyzing products, PASECO and TOYOTOMI's main products are oil heaters.

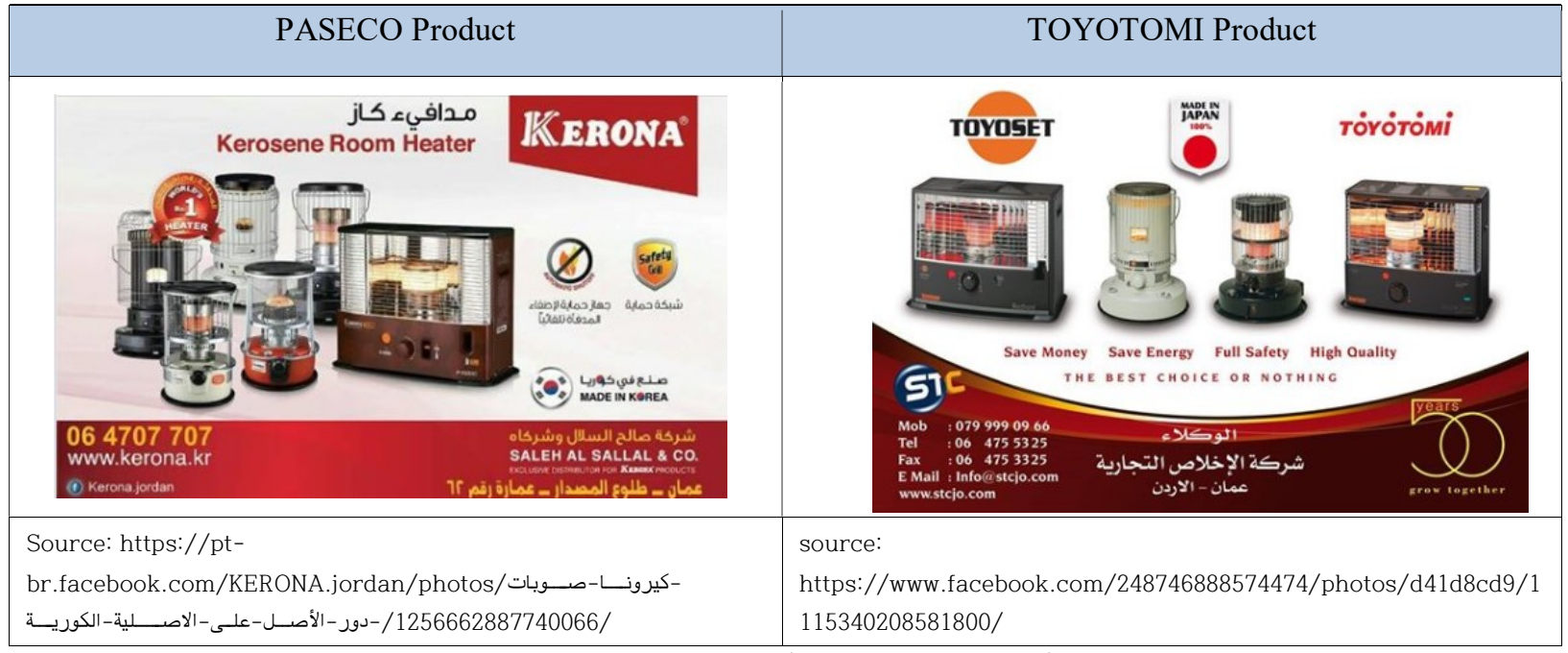

Figure 4: PASECO and TOYOTOMI Products 
PASECO's flagship products include 'PET', a portable cookable heater that was previously owned by PASECO, and WKH-2310, a product that maximizes safety functions, minimizes soot and odor. TOYOTOMI has launched the PONDA, a model that has built a high market share in Chile and maximizes heat emissions and fuel tank capacity. In addition, OMNI, which was made to respond to PASECO's 'PET' product, was composed of main products.

PASECO developed a safety function that consumers want, automatic fire extinguishing system, minimized the soot smell that was a weakness of Japanese companies, and released reasonable prices and efficient products. TOYOTOMI competed through advanced products that maximized the capacity of the fuel tank and the heat emission quantity, which is considered essential and basic function of the heater.

Comparing the prices of the two products, PASECO's products are pursuing both differentiation and cost advantage strategies. PASECO obtained patents for 'glass fiber wick' and 'automatic fire extinguishing equipment ' through continuous R\&D investments to achieve product differentiation. The company was able to produce its own with these core technologies, saving cost because unlike Japanese companies, it did not have to pay patent fees for existing Belgian companies. The PET's price, PASECO's product, is $\$ 9.95$ and OMNI's price, TOYOTOMI's product, is \$28. In addition, WKH-2310 is \$11.95 and PONDA is \$38. So, PASECO products maintain a lower price compared to TOYOTOMI products. Comparing and analyzing the place and promotion strategies of the two companies, both ran professional dealerships as export-oriented companies. However, unlike TOYOTOMI, PASECO attempted to make more contact with customers through distribution to large retailers. In Promotion, PASECO raised awareness from customers by directly seeking out customers and promoting products, and TOYOTOMI wanted to be noticed by large buyers through world fairs and exhibitions.

\subsection{SWOT}

When PASECO entered the Middle East, it looked at the analysis of the external and internal environment. Based on this analysis, this part will summarize it into the SWOT framework to see what strengths, weaknesses, opportunities, and threats PASECO had in the Middle East.

First, looking at PASECO's strengths. The product of KERONA, PASECO's brand in the Middle East, was able to position itself as a strong technology and cost-effectiveness product through PET, a portable cookheater that identified and developed the needs of Jordanian consumers when entering the Middle East. In particular, the technology was demonstrated through the development of key components such as shape memory alloy technology and automatic extinguishing device, which were obtained through continuous $\mathrm{R} \& \mathrm{D}$, and the entry barrier was established in the industry. As one of KERONA's core capabilities, the two-way communication with customers continues from the beginning to the present, was able to build trust with customers to create an image of a company called 'premium' and to achieve the top market share in the Middle East.

Second, its main competitor, TOYOTOMI, which started the heater business about 40 years earlier than KERONA, can be seen as an advantage by increasing 'heat emission' and 'fuel tank capacity' through technical know-how. In addition, the brand image of Japanese products was higher than that of PASECO when it entered the Middle East market. Also, China's price competitiveness with Chinese counterfeit companies' capital was a weak point in the long run.

Third, it is the opportunity factor. Jordan has many desert and nomadic characteristics. Oil heaters are used as a necessity for nomadic tribes that travel once a month and for desert areas where gas and electricity are not supplied properly. In Iraq, the fact that the state provides a certain amount of oil free of charge (50 liters per year) is one reason why oil heaters are preferred over gas or electric ones, which are suggested as alternatives. The sensitivity of the exchange rate also served as an opportunity factor, as it was able to export at a relatively low exchange rate compared to its main rival, TOYOTOMI, a Japanese firm.

Finally, it is the threat factors. Due to the nature of the oil heater industry, it is greatly affected by the climate. These seasonal limitations are one of the biggest threats and are a challenge not only for PASECO but also for all companies. To overcome these seasonal limitations, PASECO chose to diversify its business into the built-in consumer electronics industry. There are many small and large conflicts in the Middle East because of the problems of religion and oil. An example is the Israeli-Palestinian conflict. In addition, the Iraqi region is located in the PASECO's presence and neighboring countries, causing international conflict and posing a political and social threat to the Middle East. As the environmental pollution problem of fossil fuels such as coal and oil becomes serious and technology advances, the number of alternative energy sources such as solar, bioenergy and wind energy that can replace oil heaters is increasing, and these are threat factors. 


\section{Conclusions}

Since its foundation in 1974, PASECO has been steadily pursuing a comprehensive home appliance company that produces oil heaters and home appliances for more than 40 years. Based on its technological power of oil heater industry accumulated through producing oil heaters wicks, PASECO succeeds in transforming itself into a home appliance company that produces oil heaters from the 80s. Despite the difficulties caused by the changes in the housing culture in Korea, the company developed glass fiber wick by focusing on technological development. PASECO was also able to set the stage for the world by acquiring U.S. safety standards, which competitors have also failed.

The success factors of PASECO are as follows. First, it is high technical and better quality than competitors. Based on his experience selling oil heaters to the U.S. and the Middle East with excellent quality competitiveness, PASECO finds that oil heaters, which had been on the decline in Korea, are still becoming an important heating tool overseas. If PASECO had stayed at home country, PASECO would not have known that oil heaters, which are only found in rural areas in Korea, are still used by many people in the U.S., a more advanced country than Korea. Also, in the Middle East, a hot desert country, it would have been hard to see that oil heaters are considered necessities of life and that Japanese companies are already making a lot of profit from their entry. If PASECO had failed to improve quality through efforts to pass tough U.S. certification standards, PASECO would not have become the world's No. 1 product of his own brand, which all small and medium-sized companies dream of.

Second, PASECO's method of seeking opportunities by constantly exploring markets and customers led the growth of companies through localized products. By closely monitoring the lifestyle of nomadic customers in the Middle East, PASECO was able to develop a "PET", a heater that not only heating but also cooking at the same time. PASECO not only improved customer satisfaction by setting up the customer service center to quickly resolve problems arising from the specificity of the Middle East, but also learned new technical know-how in solving problems raised by customers.

Third, PASECO had the ability to create new opportunities by closely looking at markets and customers. When other local rivals gave up their businesses as the oil-heater industry declined, PASECO began exporting oil heaters to the United States and the Middle East, knowing there were bigger markets abroad. In the process of targeting unfamiliar markets abroad, PASECO was able to create localized products suitable for different cultures and environments and accumulate new technological know-how. These were possible because PASECO has been constantly looking closely at markets and customers to try to find hidden opportunities.

The ultimate goal of companies that have started with OEM/ODM methods is to grow into OBM companies with their own brands. Companies can achieve their goals only by analyzing markets and customers and accumulating the experience of finding the right approach. PASECO is analyzing customers' needs with a nationwide A/S network and a systematic system at its next-generation main business, Built-in home appliance. The information gathered in this process has also been reflected in the development of new products, making PASECO the foundation for rapid growth. In addition, this market and customer-oriented management will be a competitive edge that other companies will not be able to overcome in future growth. As such, PASECO's success strategy presents an important managerial implication for companies.

\section{Reference}

Ahn, J, K. (2013). PASECO, Selling oil heater in the desert. HanKyung. 28 November, Section 2-3. Seoul, Korea.

Cho, H. J., Choi, I. H., \& Kim, H. G. (2016). Emergence of PASECO as a global appliance company form a kerosence heater wick. Business Education Review, 31(6), 173-201.

Herald Economy News (2019). PASECO's heater export to U.S. and the Middle East. Herald Economy, 12 June, Section 4-5. Seoul, Korea.

Jin, B. H., Jung, J. E., Jung, S. W., \& Yang, H. S. (2015). Brand swallows the world: DNA of the success of small and medium-sized Korean small and medium-sized businesses. Seoul, Korea: Edam-Books.

Jung, B. H. (2010). A Case Study on Developing a Global Market by Developing New Products: Kerosene wick heater. Proceedings of 2010 Integrated Conference of KASBA (pp.12-32). Seoul, Korea: KASBA.

Kang, M. S. (2014). 2014 Success Story. IBK Economic Research Institute, 1(4), 170-197.

KBS (2005). Sell the oil heater in the land of the heathen! Korea's No. 1 exporter of oil heaters to the global market - PASECO. KBS Special Myth Creation Program

Kim, J. H. (2018). PASECO's Business Strategy. ZITA, 3 May, Section 7-8. Seoul, Korea. 
Kim, Y. J. (2010). Iraq, high demand for kerosene heater. KOTRA.

Korea Investor Relations Service (2018). Technical analysis report for PASECO. Korea corporate data, Retrieved October 25 from http://w3.kirs.or.kr/download/tech/315 \%ED\%8C\%8C\%EC\%84\%B8\%EC\%BD\%94_\%EA\%B 8\%B0\%EC\%88\%A0\%EB\%B6\%84\%EC\%84\%9D\%EB\%B3\%B4\%EA\%B3\%A0\%EC\%84\%9C.pdf

Lee, B. M. (2017). "Perfect" "Ace" is in front of the English word, plus a smart home appliance company, PASECO. Financial News, 29 October, Section 2-3. Seoul, Korea.

Lee, S. H. (2015). PASECO, 45\% market share of U.S. Kerosene heater, 'unrivaled'. Maeil Business News, 11 November, Section 2-3. Seoul, Korea.

Lee. J. Y. (2016). Sell oil heaters in the desert? Paceco, the world's No. 1 oil company. Ministry of Trade, Industry and Energy. Retrieved September 29 from http://blog.naver.com/PostView.nhn?blogId=mocienews\& $\log \mathrm{No}=220886703667 \&$ parentCategoryNo=\&categor $\mathrm{yNo}=87 \&$ viewDate $=\&$ is ShowPopularPosts $=$ true $\&$ from $=$ search

Myoung, S. Y. (2010). PASECO, the world's No. 1 oil heater company in the Middle East. MaeKyoung Economy, 31 May, Section 6-7. Seoul, Korea.

Oh, K. J. (1999). PASECO, The world's No.1 kerosene heater, market share 35\%. Hankyung, 2 November, Section 6-7. Seoul, Korea.

Porter, M. E. (2008). The five competitive forces that shape strategy. Harvard Business Reviews, 86(1), 137-145.

Seo, E. N. (2018). PASECO, the No. 1 kerosene heater, a second leap. The bell, 5 April, Section 3-4. Seoul, Korea.

Won, B. C. (2010). Sanzai, which is becoming more sophisticated, needs countermeasures. Security World, 31 December, Section 2-3. Seoul, Korea. 